\title{
EDITORIAL
}

\section{Are Presentations at ASMS Conferences Publications?}

$\mathrm{T}^{\mathrm{h}}$ his editorial addresses whether or not presentations at ASMS conferences are considered to be publications. It is indeed an important question to ask, especially given the increasing rate that conferences capture unpublished material, digitize it, and provide it to either private (e.g., members-only on a secure website) or public audiences. The answer is straightforward if unpublished material is placed in the public domain - it is now considered published without question. Thus, if you present your research at the annual meeting of the American Society for Mass Spectrometry (ASMS) and then decide to post it on your website, it is then considered published and, therefore, not publishable in a peer-reviewed journal. Clearly, it is critically important to keep your publishable material out of the public domain until you are ready to publish it in peer-reviewed journals.

As one can imagine, the health of ASMS or any scientific society is based on the open exchange of data and ideas, for example at the annual meeting of the ASMS. This promotes and drives science by permitting authors to obtain multiple perspectives from others working in the field and is vital to ASMS and its members. The policy of ASMS regarding presentation and archiving of your work, including extended abstracts, oral presentations, and posters, has always been that the ASMS Proceedings is an "official record of the annual meeting" [1] but does not constitute a publication. In fact, when printed copies of the Proceedings were the media for dissemination, the following citation notice was included inside the front cover: "This volume contains the extended abstracts of papers presented at the 40th ASMS Conference on Mass Spectrometry and Allied Topics. The material is not copyrighted and appearance of material in this volume does not jeopardize the author's right to publish the information in scientific journals" [1].

This citation notice is very clear, but does the ASMS have the authority to make such a statement? Is it not really up to the scientific journals in which you intend to publish to make that decision?

This issue has become even more important as ASMS has provided alternatives to extended abstracts (which are still optional) and now allows submission of complete oral or poster presentations. It is important to keep in mind that when you submit an abstract to ASMS to be presented at the annual meeting, you must confirm that you have not published this work at the time of submission, which is about 4 to

Correspondence to: David C. Muddiman; e-mail: dcmuddim@ncsu.edu
5 months prior to the meeting. This creates a dichotomy: you can't present previously published work on one hand but on the other hand, archiving might prevent you from publishing in the future. An extended abstract is a safe way to proceed because it does not contain all the information about your research but, rather, documents your findings in a general manner that is not sufficient to reproduce the research. One could argue that slides from an oral presentation or even a complete poster also does not contain enough information to reproduce the work, making a peer-reviewed publication a necessary (to enable someone to reproduce the results) and viable outcome.

What should you do when it comes to archiving the work you presented at ASMS or any other meeting? Several journal editors were contacted and asked for their thoughts regarding presentation and subsequent archiving. The feedback was that the majority of journals seemed willing to accept material that had been presented at the ASMS Conference and subsequently archived for member-only viewing, for peer-review, and possible publication. However, it is clear that this decision is journal- and even article-typespecific and may depend on how detailed the archived record is. For example, the Journal of the American Chemical Society will not accept the work as a Communication if the essence of the new material was disclosed in an abstract, but on case-bycase basis, would consider the research for a full paper [2]. Some journals, (e.g., Science (http://www.sciencemag.org/site/ help/authors/embargo.xhtml) and Nature (http:// www.nature.com/nature/authors/policy/embargo.html)) have an embargo policy that allows presentation of the research at conferences of professional societies but not to the media or popular press. However, it remains unclear how these journals would react to having an entire oral presentation or poster containing the essence of the work published on a member-only website. Furthermore, members of the press usually attend scientific meetings such as ASMS, and journals have specific policies for how to deal effectively with this (http://www.sciencemag.org/site/help/ authors/embargo.xhtml, http://www.nature.com/nature/authors/policy/embargo.html).

This editorial seeks to alert ASMS members that these issues need to be considered prior to presenting your research and subsequent submission of an entire poster or oral presentation for archiving as a "record" of the society and its conferences. For some of you, the ASMS archive is the only communication of your results. Broadly speaking, there are no major concerns related to presenting at ASMS; however, given that ASMS provides the means to archive 
your presentation in different formats, including extended abstracts, the nature of your record is your personal choice and something you should carefully consider.

\section{David C. Muddiman}

ASMS Member-at-Large for Publications

W. M. Keck Fourier Transform Mass Spectrometry Laboratory Department of Chemistry

North Carolina State University

Raleigh, NC

E-mail: dcmuddim@ncsu.edu
Susan T. Weintraub

\section{ASMS President}

Department of Biochemistry

The University of Texas Health Science Center at San Antonio

San Antonio, TX

E-mail: weintraub@uthscsa.edu

\section{References}

1. Proceedings of the 40th ASMS Conference on Mass Spectrometry and Allied Topics, Washington, DC, May 31- June 5, 1992.

2. Personal Communication with Professor P.J. Stang, Editor of J. Am. Chem. Soc. 